\title{
Association between condom use and HIV infection: a randomised study of self reported condom use measures
}

\author{
Sharon S Weir, Ronald E Roddy, Leopold Zekeng, Kelley A Ryan
}

\begin{abstract}
Study objective-To compare the association between different measures of condom use and prevalent HIV infection. Design-Randomised cross sectional study to assess association between HIV infection and different measures of self reported condom use. Female sex workers were randomised to one of five different face to face questionnaires on condom use. Three questionnaires used always to never scales to measure use but differed in the reference period for use; a fourth asked about use in the last 10 coital acts; and the fifth was a retrospective log of coital acts in the past two weeks. Use was assessed with new clients, repeat clients, and non-clients.

Setting-Yaoundé and Douala, Cameroon.

Participants-2266 female sex workers. Main results-The association between condom use and prevalent HIV infection varied for different measures of condom use. None of the five level measures showed a dose response protective effect of condom use. Measures aimed at reducing recall bias (measures based on the past 10 coital acts or a coital log) showed little or no association with prevalent infection. Measures based on the past month or six months had a stronger association with prevalent infection. Regardless of the type of measure or reference period, the strongest association between use and infection was for use with partners who were not clients.

Conclusion-These findings underscore challenges described by others of measuring condom use and interpreting the association between use and prevalent infection.

(F Epidemiol Community Health 1999;53:417-422)
\end{abstract}

Family Health

International, PO Box

13950, Durham, NC,

27709 USA

S S Weir

R E Roddy

K A Ryan

Ministry of Health, Yaoundé, Cameroon L Zekeng

Correspondence to: Dr S S Weir

Accepted for publication 18 November 1998 interview, anonymous reports; (2) the reference period for which use is measured (for example, use in the past month); (3) whether frequency of use is determined by calculating a percentage of acts protected or by more qualitative scales ranging from always to never use; and (4) whether the measure will be general and include all partners or whether separate measures will be obtained for different types of partners (for example, steady versus occasional partners). Investigators must weigh the cost of data collection, the sophistication of the interviewers, and respondent burden against the measure's expected validity and epidemiological relevance. ${ }^{4}$

Unfortunately, the most relevant measures of condom use for many epidemiological investigations seem quite susceptible to recall and self presentation bias. ${ }^{5}$ Retrospective studies may require people to recall condom use during an exposure period extending for months or years. The follow up period in prospective studies is rarely less than a month and often much longer. However, the reliability of self reported sexual behaviour has been found to decrease as the length of the recall period increases to more than one or two weeks. ${ }^{6-8}$

Self presentation bias has also plagued the interpretation of associations between sexually transmitted disease and condom use..$^{9-11}$ Overreporting condom use has been found when measures of use are obtained in face to face interviews, in settings where condom use is openly promoted, and when respondents want to please study investigators-factors commonly in effect during an epidemiological study. ${ }^{11}{ }^{12}$ Self presentation bias may also reduce the likelihood that multiple partnerships will be reported and consequently that the lack of condom use in these relationships will be reported. Thus, although it appears that an epidemiologically relevant measure of condom use would be a measure accurately reflecting use in all partnerships over the entire period of exposure to HIV, the self reported level of use obtained for these measures is likely to be biased in ways difficult to assess.

Several strategies to develop less biased measures of use have been suggested. ${ }^{411}{ }^{13}$ These have included shortening the reference period, using calendars or coital diaries as memory aids, and framing questions and responses to avoid self presentation bias (for example, avoiding attractive responses such as "I always use condoms" and unattractive responses such as "I never use condoms"). Such measures may have limited epidemiological relevance, however, if they do 
Table 1 Characteristics of condom use measures obtained in each questionnaire

\begin{tabular}{|c|c|c|c|}
\hline $\begin{array}{l}\text { Name of } \\
\text { questionnaire }\end{array}$ & Type of measure & Reference period & Obtained for use with: \\
\hline "Current" & Always to never scale & Current & $\begin{array}{l}\text { All partners, new clients, } \\
\text { repeat clients, non-clients }\end{array}$ \\
\hline "Past month" & Always to never scale & $\begin{array}{l}\text { Use during past } \\
\text { month }\end{array}$ & $\begin{array}{l}\text { All partners, new clients, } \\
\text { repeat clients, non-clients }\end{array}$ \\
\hline "Past 6 months" & Always to never scale & $\begin{array}{l}\text { Use during past } \\
6 \text { months }\end{array}$ & $\begin{array}{l}\text { All partners, new clients, } \\
\text { repeat clients, non-clients }\end{array}$ \\
\hline "Last 10 acts" & $\%$ of use in last 10 acts & None specified & All partners \\
\hline "Coital Log" & Retrospective coital log & 2 weeks & $\begin{array}{l}\text { All partners, new clients, } \\
\text { repeat clients, non-clients }\end{array}$ \\
\hline
\end{tabular}

not reflect condom use during the period of exposure to HIV. For example, reported condom use at last coitus may be a valid and reliable measure, but not at all useful in categorising a person's condom use during the months of exposure to HIV.

In this randomised study, we empirically assessed differences in the association between prevalent HIV and measures of condom use that varied in their expected bias and epidemiological relevance. Previous research with this study population found that the reported level of use differed by type of measure. ${ }^{13}$ In this study we compared the association between HIV infection and three types of self reported measures: use according to always to never scales; use based on retrospective coital logs; and use based on how many of the last 10 coital acts were reportedly protected by a condom. We compared three different reference periods for always to never measures: the past month; the past six months; and current use without specifying a period. For the measures based on an always to never scale and coital logs, we measured use with all partners and with three types of partners thought to comprise the universe of partnerships: new clients; repeat clients; and non-paying partners such as a spouse or boyfriend. Firstly, we compared the association between use and HIV infection without taking into account the number of years in sex work; then we assessed

Table 2 Characteristics of female sex workers by questionnaire group, Cameroon, 1995

\begin{tabular}{|c|c|c|c|c|c|}
\hline \multirow[b]{2}{*}{ Characteristics } & \multicolumn{5}{|c|}{ Questionnaire group } \\
\hline & $\begin{array}{l}\text { Current } \\
\text { (460) }\end{array}$ & $\begin{array}{l}\text { Past month } \\
(464)\end{array}$ & $\begin{array}{l}\text { Past } 6 \text { months } \\
\text { (459) }\end{array}$ & $\begin{array}{l}\text { Last } 10 \text { acts } \\
(442)\end{array}$ & $\begin{array}{l}\text { Coital log } \\
(441)\end{array}$ \\
\hline $\begin{array}{l}\text { HIV prevalence } \\
\text { Age }\end{array}$ & 20.2 & 16.4 & 18.5 & 17.4 & 17.9 \\
\hline $\begin{array}{l}18-20 \\
21-25 \\
26-29 \\
30-45\end{array}$ & $\begin{array}{l}21.4 \\
36.2 \\
19.2 \\
23.3\end{array}$ & $\begin{array}{l}19.4 \\
37.3 \\
20.0 \\
23.3\end{array}$ & $\begin{array}{l}23.5 \\
36.4 \\
18.7 \\
21.4\end{array}$ & $\begin{array}{l}17.9 \\
38.6 \\
19.3 \\
24.3\end{array}$ & $\begin{array}{l}20.6 \\
40.8 \\
17.5 \\
21.1\end{array}$ \\
\hline & 100.0 & 100.0 & 100.0 & 100.0 & 100.0 \\
\hline \multicolumn{6}{|l|}{ Education } \\
\hline None & 1.1 & 1.1 & 2.4 & 1.4 & 0.7 \\
\hline Primary & 25.5 & 19.2 & 21.4 & 20.8 & 19.5 \\
\hline Middle school & 51.6 & 54.7 & 53.4 & 54.3 & 55.3 \\
\hline High school & 19.6 & 22.6 & 21.8 & 21.3 & 22.4 \\
\hline Other & 2.2 & 2.4 & 1.1 & 2.3 & 2.0 \\
\hline & 100.0 & 100.0 & 100.0 & 100.0 & 100.0 \\
\hline \multicolumn{5}{|l|}{ Years in sex work } & 49.7 \\
\hline \multirow[t]{2}{*}{3 or more } & 52.1 & 53.9 & 51.6 & 52.9 & 50.3 \\
\hline & 100.0 & 100.0 & 100.0 & 100.0 & 100.0 \\
\hline$\%$ Ever used condom & 92.6 & 94.0 & 91.9 & 89.8 & 90.0 \\
\hline$\%$ Used with last client & 45.1 & 49.7 & 44.7 & 44.6 & 43.5 \\
\hline$\%$ With last non-client & 18.3 & 20.7 & 20.7 & 18.2 & 19.3 \\
\hline
\end{tabular}

the association for those in sex work less than three years compared with more than three years.

We randomised the women to obtain groups with similar HIV prevalence, sexual frequency, partnerships, and condom use. Consequently, we attribute differences in the association between measures of condom use and HIV infection to differences in the measures and not to selection bias or confounding.

\section{Methods}

This study was part of the screening phase of a randomised controlled study among female sex workers aged 18-45 in Yaoundé and Douala, Cameroon to measure the effect of nonoxynol-9 (N-9) on HIV acquisition. ${ }^{14}$ The 90 minute consent process informed women that they would be asked about their sexual behaviour, be physically examined and tested for evidence of infection. Women who consented were interviewed about their sociodemographic characteristics and asked a few limited questions about their use of condoms including whether the respondent had ever heard of condoms, ever used them, and whether she had used one with the most recent client. Then each woman was randomised to receive one of five different questionnaires on condom use. Random assignment was done in block sizes of 10 to assure equal assignment to each group throughout the study and was done independently within each of the three clinics where women were screened. Computer generated labels identifying the questionnaire to be used were printed and sealed in envelopes at Family Health International and sequentially distributed to interviewers when needed to complete the supplemental condom questionnaire. The randomisation was designed to select five groups of approximately equal size with similar levels of condom use and exposure to HIV.

Each of the five questionnaires measured condom use in several ways (table 1). Three questionnaires asked the respondent for four types of partners (all partners, new clients, repeat client and non-clients): "How often do you use condoms with (type of partner)?" and recorded the response in terms of an "alwayssometimes-never" scale. Those who answered "sometimes" received a follow up question to determine if use was "almost always, more than half the time, half the time, or less than half the time" so that the final scale was a six point scale ranging from always to never with four intermediate categories. Non-clients were defined as "men who are not clients such as your husband, boyfriend, other regular partners, or anyone who does not give you money or gifts in exchange for sex." These three questionnaires differed only in terms of the reference period for condom use. The reference period for the first was unspecified, but questions were in the present tense implying current use. The reference period for the second was the past month and for the third the past six months. These three questionnaires are referred to as "Current", "Past Month", and "Past Six Months". 

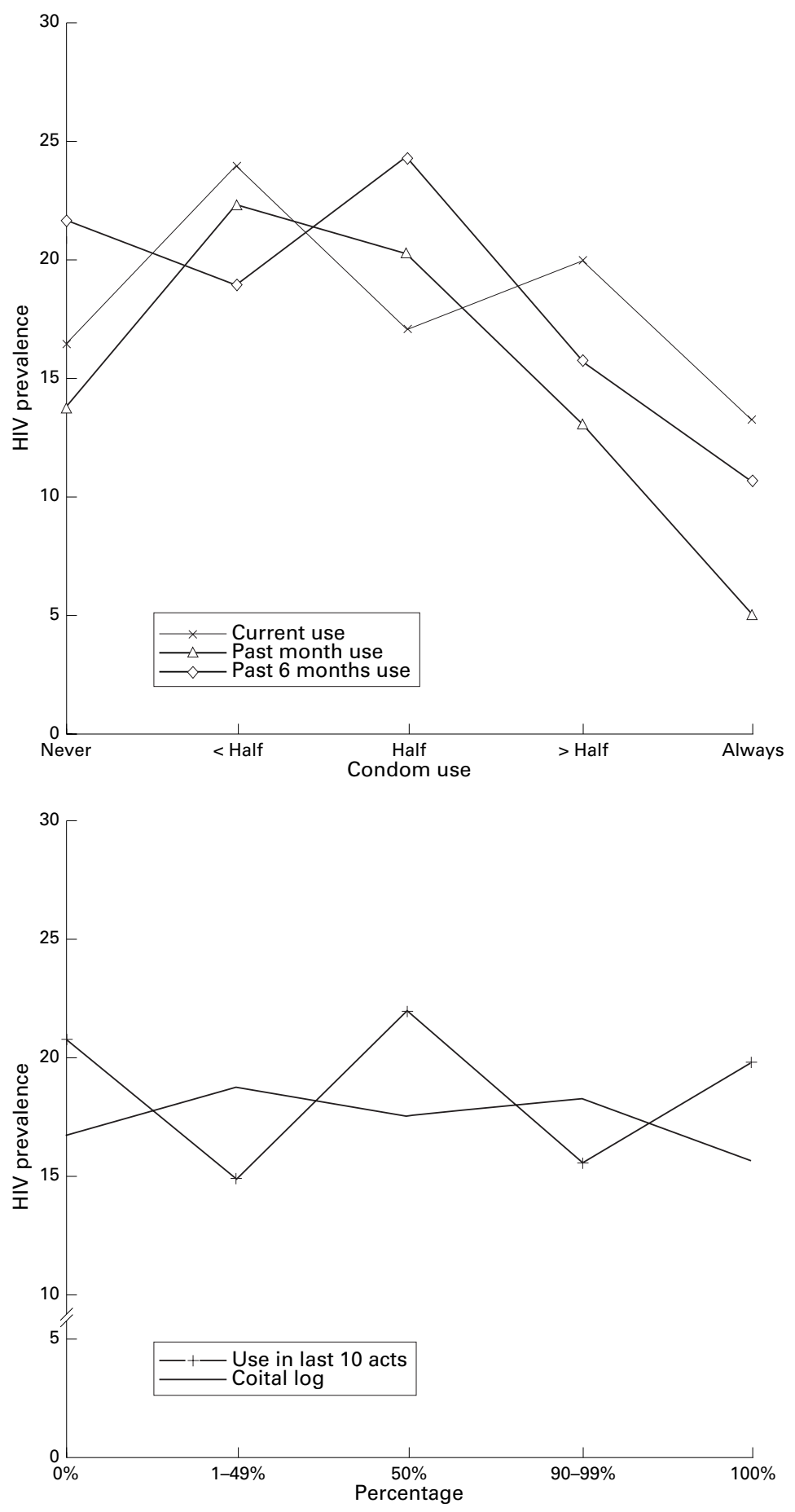

Figure 1 HIV prevalence by level of condom use with all partners.

The fourth questionnaire (referred to as "Last 10 Acts") asked the number of times condoms were used in the last 10 acts irrespective of type of partner. The fifth was a retrospective coital log (referred to as "Coital Log") that asked the respondent to sequentially recall each partner in the past two weeks. For each partner, the type of relationship, the number of coital acts, and whether or not a condom was used for each act was recorded in the log up to a maximum of eight clients with three acts apiece and two non-clients with five acts apiece. The categorisation for percentage of use reported by the Coital Log and Last 10 Acts questionnaires was defined to parallel the six level always to never scale, (that is, "always" $=100$ per cent use; "almost always" $=90-99$ per cent use; "more than half" $=51-89$ per cent use; "half of the time" $=50$ per cent use; "less than half of the time" $=$ one to 49 per cent use; and "never" = zero per cent use). All interviewers received training in how to administer each questionnaire.

The women did not know their HIV status when we conducted the baseline interviews. The women who agreed to participate in the study were tested first by enzyme linked immunosorbent assay (ELISA). Those found positive were confirmed with an additional ELISA and western blot. All women were asked to return in one month to learn the results of their test. Those who were not infected underwent another informed consent process for enrollment in a larger randomised controlled trial of nonoxynol-9 and were tested again. We considered women who had been negative at the time of the first test but positive at the time of the second test one month later as infected with HIV at the time of the first test.

We assessed the association between HIV infection and level of condom use graphically, using the row mean score statistic available in $\mathrm{SAS}^{15}$ and by estimating odds ratios and $95 \%$ confidence intervals.

\section{Results}

A total of 2266 women were tested for evidence of HIV infection and randomised to one of the five condom use questionnaires (table 1). There were no significant differences in the prevalence of HIV infection or other characteristics by questionnaire group (table 2). Almost all of the women in each group had used condoms. The percentage using a condom with the last client ranged from $43.5 \%$ to $49.7 \%$ and with the last non-client from 18.2 to $20.7 \%$, indicating that the groups had similar condom use behaviours. About half of the women in each group had been in sex work less than three years. Overall, $18.1 \%$ of the women had evidence of infection at the time of screening (including 15 women initially HIV negative but HIV positive one month later).

\section{USE WITH ALL PARTNERS}

None of the five level measures of condom use with all partners showed clear dose response protective effects for condom use (fig 1). For none of the measures was prevalence highest among "never" users. Instead, the prevalence of infection was consistently highest among "half" or "less than half the time" users. When use was measured with a coital log or during the last 10 acts, there was little association between use and infection. When measured with a coital $\log$, the prevalence of infection varied less than $4 \%$ (15.7 to $18.8 \%$ ) among all reported levels of use with all partners. (The prevalence of infection varied more within categories of use with new clients, repeat clients, and non-clients, but the prevalence of infection was never lowest among 100\% users; nor did it decrease with increasing use over three or more 
Table 3 Prevalence of HIV infection by level of condom use with all types of partners

\begin{tabular}{|c|c|c|c|c|c|}
\hline \multirow[b]{2}{*}{ Level of use } & \multicolumn{5}{|c|}{ Questionnaire group } \\
\hline & $\begin{array}{l}\text { Current } \\
\% \mathrm{HIV}+(n)\end{array}$ & $\begin{array}{l}\text { One month } \\
\% \mathrm{HIV+}(n)\end{array}$ & $\begin{array}{l}\text { Six month } \\
\% \mathrm{HIV}+(n)\end{array}$ & $\begin{array}{l}10 \text { acts } \\
\% \text { HIV+ (n) }\end{array}$ & $\begin{array}{l}\log \\
\% H I V+(n)\end{array}$ \\
\hline \multicolumn{6}{|l|}{ With all partners } \\
\hline Always & $13.3(30)$ & $5.1(65)$ & $11.1(27)$ & 20.9 (43) & $15.7(51)$ \\
\hline More than half & $20.0(170)$ & $13.1(148)$ & $15.8(158)$ & $14.9(168)$ & $18.3(142)$ \\
\hline Half & $17.1(76)$ & $20.3(59)$ & $24.3(70)$ & $22.0(50)$ & $17.6(17)$ \\
\hline Less than half & $24.0(150)$ & $22.3(153)$ & $19.0(158)$ & $15.6(90)$ & $18.8(101)$ \\
\hline Never & $16.6(34)$ & $13.8(39)$ & $21.7(46)$ & $19.8(91)$ & 16.8 \\
\hline \multicolumn{6}{|l|}{ With new clients } \\
\hline Always & $15.6(160)$ & $12.5(144)$ & $11.8(136)$ & & $17.4(132)$ \\
\hline More than half & $25.6(90)$ & $15.7(83)$ & $20.2(99)$ & & $24.0(79)$ \\
\hline Half & $25.0(60)$ & $27.3(44)$ & $25.0(56)$ & & $21.4(14)$ \\
\hline Less than half & $21.2(113)$ & $19.8(116)$ & $21.3(108)$ & & $15.4(52)$ \\
\hline Never & $16.7(36)$ & $14.1(71)$ & $20.3(59)$ & & $16.5(97)$ \\
\hline \multicolumn{6}{|l|}{ With repeat clients } \\
\hline Always & $11.1(81)$ & $11.1(81)$ & $5.1(78)$ & & $16.8(89)$ \\
\hline More than half & $17.4(69)$ & $17.4(69)$ & $23.7(59)$ & & $13.0(54)$ \\
\hline Half & $14.8(54)$ & $14.8(54)$ & $14.9(67)$ & & $11.8(17)$ \\
\hline Less than half & $20.5(151)$ & $20.5(151)$ & $21.2(156)$ & & $23.3(43)$ \\
\hline Never & $16.2(99)$ & $16.2(99)$ & $23.5(98)$ & & $22.3(121)$ \\
\hline \multicolumn{6}{|l|}{ With non-clients } \\
\hline Always & $5.9(17)$ & $9.7(31)$ & $13.0(23)$ & & $8.0(50)$ \\
\hline More than half & $17.2(29)$ & $4.6(22)$ & $0.0(38)$ & & $5.6(18)$ \\
\hline Half & $13.5(37)$ & $10.0(30)$ & $10.7(28)$ & & $16.7(12)$ \\
\hline Less than half & $19.4(129)$ & $11.4(105)$ & $9.4(128)$ & & $9.5(21)$ \\
\hline Never & $19.1(157)$ & $21.4(201)$ & $25.5(157)$ & & $18.8(207)$ \\
\hline
\end{tabular}

Table 4 Association between use and HIV infection by group and how use is categorised

\begin{tabular}{|c|c|c|c|c|c|c|c|c|}
\hline \multirow[b]{3}{*}{ Level of condom use } & \multicolumn{8}{|c|}{ Questionnaire Group } \\
\hline & \multicolumn{2}{|c|}{ Current } & \multicolumn{2}{|c|}{ Past month } & \multicolumn{2}{|c|}{ Past 6 months } & \multicolumn{2}{|c|}{ Coital log } \\
\hline & $O R$ & $95 \% C I$ & $O R$ & $95 \% C I$ & $O R$ & $95 \% C I$ & $O R$ & $95 \% C I$ \\
\hline \multicolumn{9}{|l|}{ All partners } \\
\hline Always $(100 \%)$ & 0.7 & $0.2,2.9$ & 0.3 & $0.1,1.6$ & 0.4 & $0.1,1.8$ & 0.9 & $0.4,2.3$ \\
\hline Some $(1-99 \%)$ & 1.2 & $0.5,3.1$ & 1.3 & $0.6,2.9$ & 0.8 & $0.4,1.7$ & 1.1 & $0.6,2.0$ \\
\hline Never $(0 \%)$ & 1.0 & & 1.0 & & 1.0 & & 1.0 & \\
\hline Always $(100 \%)$ & 0.6 & $0.2,1.7$ & 0.2 & $0.1,0.8$ & 0.5 & $0.1,1.6$ & 0.9 & $0.4,2.0$ \\
\hline$>$ Half $(51-99 \%)$ & 0.9 & $0.6,1.5$ & 0.6 & $0.3,1.1$ & 0.7 & $0.4,1.2$ & 1.0 & $0.6,1.8$ \\
\hline$\leqslant$ Half $(0-50 \%)$ & 1.0 & & 1.0 & & 1.0 & & 1.0 & \\
\hline \multicolumn{9}{|l|}{ New clients } \\
\hline Always $(100 \%)$ & 0.9 & $0.3,2.5$ & 0.9 & $0.4,2.0$ & 0.5 & $0.2,1.2$ & 1.1 & $0.5,2.2$ \\
\hline Some $(1-99 \%)$ & 1.5 & $0.6,3.9$ & 1.5 & $0.7,3.1$ & 1.1 & $0.5,2.2$ & 1.3 & $0.7,2.6$ \\
\hline Never $(0 \%)$ & 1.0 & & 1.0 & & 1.0 & & 1.0 & \\
\hline Always $(100 \%)$ & 0.7 & $0.4,1.2$ & 0.6 & $0.3,1.1$ & 0.5 & $0.3,0.9$ & 1.0 & $0.6,2.0$ \\
\hline$>$ Half $(51-99 \%)$ & 1.3 & $0.7,2.2$ & 0.8 & $0.4,1.5$ & 0.9 & $0.5,1.6$ & 1.6 & $0.8,3.1$ \\
\hline$\leqslant$ Half $(0-50 \%)$ & 1.0 & & 1.0 & & 1.0 & & 1.0 & \\
\hline \multicolumn{9}{|l|}{ Repeat clients } \\
\hline Âlways $(100 \%)$ & 0.8 & $0.4,1.9$ & 0.6 & $0.3,1.5$ & 0.2 & $0.1,0.5$ & 0.7 & $0.3,1.4$ \\
\hline Some $(1-99 \%)$ & 1.1 & $0.6,2.1$ & 1.2 & $0.6,2.2$ & 0.8 & $0.5,1.5$ & 0.7 & $0.4,1.3$ \\
\hline Never $(0 \%)$ & 1.0 & & 1.0 & & 1.0 & & 1.0 & \\
\hline Always $(100 \%)$ & 0.8 & $0.4,1.5$ & 0.6 & $0.3,1.2$ & 0.2 & $0.1,0.5$ & 0.7 & $0.4,1.4$ \\
\hline$>$ Half $(51-99 \%)$ & 1.1 & $0.6,2.1$ & 1.0 & $0.5,1.9$ & 1.2 & $0.6,2.3$ & 0.5 & $0.2,1.3$ \\
\hline$\leqslant$ Half $(0-50 \%)$ & 1.0 & & 1.0 & & 1.0 & & 1.0 & \\
\hline \multicolumn{9}{|l|}{ Non-clients } \\
\hline Always $(100 \%)$ & 0.3 & $0.0,1.8$ & 0.4 & $0.1,1.3$ & 0.4 & $0.1,1.5$ & 0.4 & $0.1,1.1$ \\
\hline Some $(1-99 \%)$ & 0.9 & $0.5,1.6$ & 0.4 & $0.2,0.8$ & 0.2 & $0.1,0.4$ & 0.5 & $0.2,1.2$ \\
\hline Never $(0 \%)$ & 1.0 & & 1.0 & & 1.0 & & 1.0 & \\
\hline Always $(100 \%)$ & 0.3 & $0.0,1.9$ & 0.5 & $0.2,1.7$ & 0.7 & $0.2,2.4$ & 0.4 & $0.1,1.1$ \\
\hline$>$ Half $(51-99 \%)$ & 0.9 & $0.3,2.5$ & 0.2 & $0.0,1.5$ & $\star$ & & 0.3 & $0.0,1.8$ \\
\hline$\leqslant$ Half $(0-50 \%)$ & 1.0 & & 1.0 & & 1.0 & & 1.0 & \\
\hline
\end{tabular}

* No infections in this category of use.

adjacent categories of use.) When use was measured based on the last 10 acts, the prevalence of infection was similar among " $100 \%$ " and " $0 \%$ " users with no consistent increase or decrease of infection in any adjacent categories of use.

REFERENCE PERIOD

The association between use and HIV infection did not differ significantly among the three always to never measures using different reference periods (table 3 ). Odds ratios overlapped substantially (table 4 ). When the analysis was restricted to women who had been in prostitu-
KEY POINTS

- Epidemiological investigations often require measuring condom use. This cross sectional study illustrates that the measure of condom use selected can affect the association between use and HIV infection.

- Condom use measures based on the last 10 acts or past two weeks may have reduced recall bias but showed little or no association with prevalent infection.

- Measures based on an always to never scale frequently showed a curvilinear association with HIV infection. "Never users" may be more likely to over-report use or have fewer sexual partners.

- Regardless of the type of measure or reference period, the strongest association between use and infection was for use with partners who were not clients.

tion less than three years, these results did not change (data not shown). However, of the three measures, the association between use and infection was weakest for current use of condoms. The prevalence of infection did not decrease with increasing use for any three adjacent current use categories for any type of partner. The prevalence of infection decreased as use increased over four adjacent categories for two of the four past month measures (use with all partners and non-clients). The difference in prevalence between "never" and "always" users was greatest, however, when use was measured over the past six months. This was true regardless of whether use was measured with new clients, repeat clients, nonclients or all partners. Odds ratios for "always" using condoms were also lower for six month measures (range 0.0 to 0.5 ) compared with current and past month measures (range 0.0 to $0.9)$.

CATEGORISATION OF USE

When use was measured with an always to never scale and categorised as "always", "sometimes" or "never", the association with infection was usually curvilinear (table 4). However, when recategorised as "always", "more than half the time", or "half the time or less", a stronger association between use and infection was apparent. Odds ratios (ORs) decreased with increasing level of use for half of the 12 current, past month, and past six months measures when use was recategorised this way (table 4). Neither categorisation of use showed an association between infection and use for coital log measures.

USE BY TYPE OF PARTNER

The association between HIV infection and condom use was strongest when condom use was measured with non-clients (table 4). In contrast with the association between infection and use with all partners, new clients, or repeat clients, women who reported "never" using condoms with non-clients had a higher prevalence of infection than women reporting "some" or "always" use. This was true whether 
use was measured with an always to never scale or a coital log. ORs were consistently about 0.3 to 0.7 for "always" compared with "never" use with non-clients, regardless of the type of measure or how it was categorised. ORs for "always" use with repeat clients and new clients were generally higher.

\section{Discussion}

This study found that the association between cross sectional estimates of condom use and prevalent HIV infection varied according to the measure used to estimate use.

None of the measures of condom use in this study showed a consistent dose response protective effect for condoms against HIV. In interpreting our findings, we assume that condom use reduces the risk of HIV acquisition and that failure to detect a protective effect implies that the measures of condom use suffered from recall or self presentation bias, did not reflect use during the period of actual exposure to HIV, or were confounded with other risk behaviours. The findings underscore the challenges described by others of measuring condom use and interpreting the association between use and prevalent infection. ${ }^{4} 5$ 9-11 $16-20$

The strength of this study is that we can assume, based on a successful randomisation, that the five questionnaire groups were similar in the distribution of all risk factors for HIV infection including exposure to HIV, condom use, unprotected anal sex, injection drug use, and biological susceptibility to infection. Consequently, we can attribute any differences in the strength of the association between reported level of condom use and infection to differences in how use was measured. Specifically, this study sheds light on how the estimated association between use and infection can vary based on decisions made by the investigator regarding the reference period for use, the categorisation of use and whether use is assessed for different types of partners.

Randomisation of women to different measures of condom use precluded an assessment of the individual correlation of the various measures. We chose to randomise women to different measures to eliminate any bias in responses resulting from women responding differently to subsequent questions because of their responses to initial questions. Simply changing the order of the questions within questionnaires would not have been sufficient to eliminate the bias and would have introduced new problems in interpretation. Women who first responded they always used condoms with all partners in the past six months may have felt more inclined to subsequently report they used a condom with their new clients in the past month. Asking about use in the reverse order, (that is, use in the past week, then in the past month, then in the past six months) might have provided memory clues resulting in a different response about use in the past six months than a single question.
REFERENCE PERIOD

As in most retrospective studies, we did not know when infection occurred and could not measure the association between reported use during that period and incident HIV infection. Most of the infected women in this study were undoubtedly infected before the time period for which they were asked to recall condom use (that is, only 15 of the over 400 infected women were newly infected). Measures based on a short reference period, however, can be appropriate even for older women exposed to HIV for years if the likelihood of recall bias is great and the characteristic being measured has not changed over time.

In this study, of the three always to never measures that differed only in the reference period, the weakest association with prevalent infection was for the current use measure. In fact, all of the measures that used a reference period of two weeks or less and thus minimised recall bias the most - current use, use in the last 10 coital acts, and use in the past two weeks as assessed by a coital log-had the weakest association with prevalent HIV infection. This suggests that a two week reference period is too short a time period to reflect use over the entire period of exposure to HIV. In fact, given that evidence of HIV infection is not immediately detectable with ELISA tests and averages about three weeks, use during the two weeks before testing will not be associated with infection status unless it reflects use over a longer previous period. Measures based on short recall periods may not include a sufficient number of coital acts to adequately classify the level of use. In this study, the coital logs categorised more women as either "always" or "never" users than any of the other measures. ${ }^{13}$ Women who reported only one or two acts, for example, on their coital log and used condoms each time were characterised as "always" users. Using a longer reference period may smooth out week to week fluctuations in use that may get captured by shorter reference periods and reduce the variability in the number of coital acts upon which the measure is based.

CATEGORISATION OF USE

Another decision made by the investigator that affects the estimated association between condom use and infection is how use is categorised. None of the measures showed decreasing prevalence of infection for every category of use when use was categorised into five levels. Consequently, how categories are combined for the two or three level measures typically used in stratified and logistic analysis becomes critical in assessing the association between use and infection. This is particularly important when, as frequently occurred in this study, there is a curvilinear association between use and infection.

Unfortunately, there are many possible explanations for the observed curvilinear relation between use and infection, but insufficient data to discern which are most plausible. "Never" users may have had a lower risk of infection than "sometimes" or "always" users. This would be true, for example, if "never 
users" had fewer partners, drew partners from a sub-group in the community with a lower prevalence of HIV infection, or had a lower biological susceptibility to HIV. In this study, "never" users reported fewer partners than other women (data not shown), but we did not have information on the infection status of the partners or full information on biological susceptibility to infection. "Sometimes" users may have included "never" users who overreported their use and were misclassified as "sometimes" users. Differential distribution of self presentation bias has been suggested in several studies ${ }^{511}$ and is a reasonable explanation for our findings as well.

The distinction between a curvilinear association arising from a lower exposure among "never" users and one arising from differential overreporting among "never" users is important. If "never" users were more likely to overreport use than women who sometimes or always used condoms, combining the lower use categories would help remove this bias. When we combined the three lowest use categories, the curvilinearity evident in the associations was decreased.

USE BY TYPE OF PARTNER

The only condom use measure in these data showing a consistent protective effect for condom use in all questionnaire groups - that is, regardless of how use was measured or the reference period-was using condoms with non-clients. In fact, a two week reference period may be long enough to capture a sex worker's level of condom use with her nonclient partners. The difference in use by type of partner and the strong association between lack of use with non-clients and infection may be critically important for understanding the spread of disease among "core groups" in Cameroon and its spread among the larger population. ${ }^{21-23}$

In conclusion, in this population, the association between condom use and prevalent HIV infection varied for different measures of condom use. Measures based on the last 10 acts or past two weeks may have been more reliable and reduced recall bias but showed little or no association with prevalent infection. One possible explanation is that the recall period was too short to adequately reflect use during the entire period of exposure to HIV. Measures based on an always to never scale showed a curvilinear association with HIV infection, possibly reflecting a combination of over-reporting use among never users and a lower exposure to HIV among "never users" resulting from having fewer partners. These data illustrate the importance of the decisions investigators make in specifying the reference period for condom use, the type of condom use measure, how it is categorised for analysis, and to which partner the measure refers.

Funding: this study was funded in part by the United States Agency for International Development, the Mellon Foundation, and the National Institute of Allergy and Infectious Diseases (grant AI34714)

Conflicts of interest: none.

Informed consent was obtained from each participant and the study and consent process was approved by the Protection of Human Subjects Committee at Family Health International (FHI) and the Ethics Review Committee of the Ministry of Public Health, Cameroon.

1 Feldblum PJ, Morrison CS, Roddy RE, et al. The effectiveness of barrier methods of contraception in preventing the spread of HIV. AIDS 1995;9 (suppl A):S85-93.

2 Cates W Jr, Stone KM. Family planning, sexually transmitted diseases and contraceptive choice: a literature update, part I. Family Plann Perspect 1992;24:75-84.

3 Center for Disease Control and Prevention: Update: barrier protection against HIV infection and other sexually transmitted diseases. $M M W R$ 1993;42:589-591, 597.

4 Catania JA, Gibson DR, Chitwood DD, et al. Methodological problems in AIDS behavioral research:influences on messurement error and participation bias in studies of mexual behavior. Psychol Bull 1990;108:339-62.

5 Catania JA, Binson D, Canchola J, et al. Effects of interviewer gender, interviewer choice, and item wording interviewer gender, interviewer choice, and item wording
on responses to questions concerning sexual behavior. Public Opinion Quarterly 1996;60:345-75.

6 Lagarde E, Enel C, Pison G. Reliability of reports of sexual behavior: a study of married couples in rural West Africa. Am F Epidemiol 1995:141:1194-200.

7 Ellish NJ, Weisman CS, Celentano D, et al. Reliability of partner reports of sexual history in a heterosexual population at a sexually transmitted diseases clinic. Sex Transm Dis 1996;23:446-52.

8 Kauth MR, St Lawrence JS, Kelly JA. Reliability of retrospective assessments of sexual HIV risk behavior: a comparison of biweekly, three-month, and twelve month self-reports. AIDS Educ Prev 1991;3:207-14.

9 Weir SS, Feldblum PJ. Condom use to prevent incident STDs. [Letter]. Sex Transm Dis 1996:23:76-7.

10 Zenilman JM, Weisman CS, Rompalo AM, et al. Condom use to prevent incident STDs: the validity of self-reported condom use. Sex Transm Dis 1995;22:15-21.

11 Turner CF, Miller HG. Zenilman's anomaly reconsidered. Sex Transm Dis 1997;24:522-7.

12 Weir S, Fox L, DeMoya A, et al. Measuring condom use among sex workers in the Dominican Republic. Int $\mathcal{F}$ STD among sex workers in

13 Weir SS, Roddy RE, Zekeng L, et al. Measuring condom use: asking “do you or don”t you? Isn't enough. AIDS Educ Prev 1998;10:293-302.

14 Roddy RE, Zekeng L, Ryan KA, et al. A controlled trial of nonoxynol-9 film to reduce male-to-female transmission of sexually transmitted diseases. N Engl F Med 1998;339:50410.

15 Stokes ME, Davis CS, Koch GG. Categorical data analysis using the SAS system. Cary, NC: SAS Institute Inc, 1995.

16 Konings E, Bantebya G, Carael M, et al. Validating population surveys for the measurement of HIV/STD prevention indicators. AIDS 1995;9:375-82.

17 Sheeran P, Abraham C. Measurement of condom use in 72 studies of HIV-preventive behavior:a critical review. Patient Education and Counselling 1994;24:199-216.

18 Dare OO, Cleland JG. Reliability and validity of survey data on sexual behavior. Health Transition Review 1994;4 (suppl):93-110.

19 VanLandingham $M$. HIV infection in Thailand: The use of condoms. ҒAMA 1994;272:1478-9.

20 Mertens TE, Hayes RJ. Smith PG. Epidemologic methods to study the interaction between HIV infection and other sexually transmitted diseases. AIDS 1990;4:57-66.

21 Aral SO, Holmes KK, Padian NS, et al. Overview: individual and population approaches to the epidemiology and prevention of sexually transmitted diseases and human immunodeficiency virus infection. F Infect Dis 1996; 174(suppl 2):S127-33.

22 Thomas JC, Tucker MJ. The development and use of the concept of a sexually transmitted disease core. $\mathcal{F}$ Infect Dis 1996;174(suppl 2):S134-43.

23 Rothenberg RB, Potterat JJ, Woodhouse DE. Personal risk taking and the spread of disease: beyond core groups. $\mathcal{F}$ Infect Dis 1996;174(suppl 2):S144-9. 